\title{
Medical Spending, Bequests, and Asset Dynamics around the Time of Death
}

John Bailey Jones, Mariacristina De Nardi, Eric French, Rory McGee, and Rachel Rodgers

A lmost 40 percent of U.S. wealth belongs to households whose head is sixty-five or older. ${ }^{1}$ These older households tend to run down their wealth more slowly than the rate of decrease implied by a basic life-cycle model in which the time of death is known. An active research literature has risen around this "retirement-savings puzzle" (De Nardi et al., 2016). One potential solution to this puzzle is that older households are holding their assets because they fear incurring high medical expenses at the ends of their lives. Another potential explanation is that the elderly are accumulating assets to bequeath to their heirs. ${ }^{2}$ Determining which of these motives is more powerful has proven challenging, in large part because the two motives generate similar saving behavior (Dynan et al., 2002; De Nardi et al., 2016).

One strategy for differentiating these saving motives is to analyze dissaving decisions near the end of one's life. If older households are saving to cover end-of-life medical spending, we should observe at least

\footnotetext{
John Bailey Jones: Federal Reserve Bank of Richmond, john.jones@rich.frb.org. Mariacristina De Nardi: University of Minnesota, Federal Reserve Bank of Minneapolis, CEPR, and NBER, denardim@nber.org. Eric French: UCL, CEPR, and IFS, eric.french.econ@gmail.com. Rory McGee: UCL and IFS, rory.mcgee.13@ucl.ac.uk. Rachel Rodgers: Federal Reserve Bank of Richmond, rachel.rodgers@rich.frb.org. For helpful comments we thank Brandon Fuller, Joon Kang, Claudia Macaluso, Nicolas Morales and Urvi Neelakantan. The views expressed in this paper are those of the authors and not necessarily those of the Federal Reserve Bank of Minneapolis, the Federal Reserve Bank of Richmond, the IFS, the NBER, or the CEPR.

${ }^{1}$ Calculations using net worth data from the 2016 Survey of Consumer Finances, as tabulated by the Board of Governors of the Federal Reserve System (2019), Tables 1 and 4.

${ }^{2}$ A third possibility is that the elderly place a high value on remaining in their own homes for as long as possible (Nakajima and Telyukova, 2017, 2019; Cocco and Lopes, 2019; McGee, 2019).
} 
some households incurring significant medical expenses in their final years of life and experiencing concomitant falls in their wealth. ${ }^{3}$ On the other hand, if medical expenses do not rise at the end of life and people are not concerned with leaving wealth to their heirs, we should see households consuming their assets more quickly as death becomes imminent.

In this paper, we take a first step toward such an analysis by documenting the dynamics of wealth and medical expenses around the time of a person's death, using data from the oldest cohorts of the Health and Retirement Study (HRS). To do so, we employ an event study approach. For each "treatment" household experiencing a death, we identify another, similar, "control" household that experienced a death six to ten years later. Using fixed effects regression, we then estimate the asset trajectories of the treatment households as their death approaches, along with the asset trajectories of their matched control households over the same time period. We find that in the six years preceding their deaths, the assets of singles decline on average, relative to those of survivors, by an additional $\$ 20,000$ on average. Correspondingly, over the same time span, the assets of couples who lose a spouse fall by an additional $\$ 90,000$ on average compared with those of similar surviving couples. Households experiencing a death also incur higher out-of-pocket medical spending. Elevated medical spending is sufficient to explain (in accounting terms) the asset declines observed for singles, but falls short of explaining the declines observed for couples. Bequests from the dying spouse to nonspousal heirs, such as children, are more than sufficient to explain the remainder.

Our paper is in large part a follow-up to French et al. (2006), enhanced by an additional twelve years (six waves) of data. French et al. (2006) found that the assets of single households fell by 30 percent in the year preceding death. About 37 percent of that decline was attributable to increased medical spending or burial costs. In addition to expanding the sample period, we extend this analysis to couples, examining how assets and medical spending behave when a spouse dies. The declines found by French et al. (2006) are much larger than the ones reported here; we argue below that the difference is due to changes in the data, including a (considerably) longer sample.

Other related papers include Poterba et al. (2011), who also work with HRS data. They find little dissaving among intact households but significant declines in assets when a household member dies. We

\footnotetext{
${ }^{3}$ We focus on expenses that are uninsured. For a discussion of why households concerned about medical expenses, especially long-term care, would fail to buy insurance against them, see French et al. (2018), Ameriks et al. (2018), and Braun et al. (2019).
} 
extend their analysis to better understand the importance of end-of-life expenses relative to transfers made around the time of death.

Kopczuk (2007) analyzes estate tax data (covering roughly 6 percent of U.S. adult deaths) and finds that individuals with longer terminal illnesses tend to leave smaller estates. He argues that the difference is too large to be fully explained by end-of-life expenses and concludes that the additional asset declines most likely reflect "deathbed estate planning." Kvaerner (2019) uses Norwegian administrative data to track single individuals who have been diagnosed with cancer. Because of generous public health insurance in Norway, a cancer diagnosis there signals a reduced lifespan without signaling a meaningful increase in out-of-pocket medical expenses. Kvaerner (2019) finds that individuals with a cancer diagnosis make significant inter-vivos transfers to their children as measured by asset increases of the children, which suggests that altruism is an important saving motive for the elderly. ${ }^{4}$ Suari-Andreu et al. (2019) report similar results for the Netherlands, which also has universal insurance. They find that households experiencing "non-sudden deaths" have less wealth at the time of death. Relative to these studies, an attractive aspect of our study is that we use the same dataset to measure assets, end-of-life expenses (such as medical and burial expenses), and transfers to children and others.

Poterba et al. (2017) use the HRS to estimate the "asset cost of poor health." They document that within each 1994 asset quintile, individuals in the top third of the 1994 health distribution have, in 2010, 50 percent more wealth than those in the bottom third. They argue that these differences appear too large to just reflect the direct imposition of medical expenses. De Nardi et al. (2019) reach a similar conclusion in the context of a structural model. Poterba et al. (2018) consider the distinct question of whether old-age health shocks bring down household wealth. They find that the onset of a major health condition or the death of a spouse after age sixty-five increases the likelihood of low wealth in the subsequent period, but by only a modest amount. They do not quantify the effect on asset levels.

The rest of our paper is organized as follows. In Section 1, we review the HRS data that we use in our analysis. In Section 2, we describe our empirical methodology; in Section 3, we discuss our results, and in Section 4 , we conclude.

\footnotetext{
${ }^{4}$ The choice between inter-vivos transfers-transfers made while the giver and recipient are still alive - and bequests likely depends on multiple factors. One is that intervivos transfers may allow the parties to avoid the estate tax: Kvaerner (2019) finds that inter-vivos transfers are more prevalent among the wealthy. A second is the strategic bequest motive (Bernheim et al., 1985), where parents withhold transfers to elicit care from their children. Kopczuk (2007) discusses several considerations.
} 


\section{DATA}

The data that we use were compiled as inputs for the structural model of savings for couples and singles developed and estimated in De Nardi et al. (2019). Thus, our description of the data borrows heavily from the text of that project, as well as French et al. (2006) and Jones et al. (2018).

\section{Sample Composition}

We use data from the Asset and Health Dynamics among the Oldest Old (AHEAD) cohorts of the HRS. The AHEAD is a sample of noninstitutionalized individuals age seventy or older in 1993. These individuals were interviewed in late 1993/early 1994 and again in 1995/96, 1998, 2000, 2002, 2004, 2006, 2008, 2010, 2012, and 2014. We use data for 10 waves, from 1995/96 through 2014. We exclude data from the 1994 wave because both assets and medical spending are underreported (Rohwedder et al., 2006).

We only consider retired households, defined as those earning less than $\$ 3,000$ in every wave. In our analysis, we track each household until all of its members die; attrition for other reasons is low. To streamline the interpretation of our results, the only demographic transition we consider is death. We therefore drop households that get married or divorced or report other marital transitions not consistent with our framework. We also drop households that: have large differences in ages; are same-sex couples; are cohabiting couples; have no information on the spouse; or are missing asset data. Finally, we remove observations with assets at or above the ninety-ninth percentile of the asset distribution (with separate thresholds for singles and couples). Applying these criteria leaves us with 4,169 households in 1995, of whom 1,221 are initially couples and 2,948 are singles. Some of these households are missing for reasons other than death in later waves, but the fraction never exceeds 5 percent.

Table 1 documents the demographic transitions for households that were married couples in 1995. Most couples in the AHEAD stay intact for only a few waves. By 2002, 59 percent of married households had lost one or both spouses. The modal transition for couples is to become widows (31 percent in 2002), but a significant number become widowers (11 percent) or lose both spouses (16 percent).

Table 2 shows transitions for individuals who were single in 1995. This group combines individuals who were married prior to 1995 with those who were single throughout their entire lives. As expected, women live longer than men: by 2004, over 74 percent of single men have died, as opposed to 59 percent of single women. 
Table 1 Sample Counts for Initial Couples

\begin{tabular}{lcccc}
\hline \hline Year & Intact Couples & Single Men & Single Women & Both Dead \\
\hline 1995 & $1,221(100)$ & $0(0)$ & $0(0)$ & $0(0)$ \\
1998 & $904(76)$ & $83(7)$ & $178(15)$ & $17(1)$ \\
2000 & $654(57)$ & $117(10)$ & $292(26)$ & $81(7)$ \\
2002 & $466(41)$ & $126(11)$ & $355(31)$ & $187(16)$ \\
2004 & $325(29)$ & $127(11)$ & $401(35)$ & $279(25)$ \\
2006 & $222(20)$ & $120(11)$ & $392(35)$ & $390(35)$ \\
2008 & $154(14)$ & $102(9)$ & $357(32)$ & $513(46)$ \\
2010 & $85(8)$ & $78(7)$ & $294(26)$ & $667(59)$ \\
2012 & $51(5)$ & $56(5)$ & $243(22)$ & $778(69)$ \\
2014 & $27(2)$ & $42(4)$ & $192(17)$ & $855(77)$ \\
\hline
\end{tabular}

Note: Parentheses contain sample percentages.

Table 2 Sample Counts for Initial Singles

\begin{tabular}{lcccc}
\hline & \multicolumn{1}{c}{ Single Men in $\mathbf{1 9 9 5}$} & Single Women in $\mathbf{1 9 9 5}$ \\
\hline Year & Single Men & Dead & Single Women & Dead \\
\hline 1995 & $543(100)$ & $0(0)$ & $2,405(100)$ & $0(0)$ \\
1998 & $389(75)$ & $129(25)$ & $1,902(83)$ & $379(17)$ \\
2000 & $279(53)$ & $244(47)$ & $1,544(68)$ & $729(32)$ \\
2002 & $206(39)$ & $316(61)$ & $1,211(53)$ & $1,065(47)$ \\
2004 & $136(26)$ & $388(74)$ & $935(41)$ & $1,354(59)$ \\
2006 & $103(20)$ & $424(80)$ & $688(30)$ & $1,597(70)$ \\
2008 & $59(11)$ & $467(89)$ & $508(22)$ & $1,797(78)$ \\
2010 & $36(7)$ & $497(93)$ & $322(14)$ & $1,995(86)$ \\
2012 & $26(5)$ & $508(95)$ & $230(10)$ & $2,088(90)$ \\
2014 & $15(3)$ & $518(97)$ & $140(6)$ & $2,166(94)$ \\
\hline
\end{tabular}

Note: Parentheses contain sample percentages.

\section{Variables}

The HRS includes a large number of financial variables, including detailed asset and liability measures. Table 3 shows means and medians for several asset categories, measured in 2014 dollars, for all households with at least one surviving member. The HRS wealth data have the usual rightward skew, with mean values well in excess of medians. Most notably, the median household holds no stocks whatsoever, while stockholdings are in some waves the second-largest component of mean wealth.

An important feature of the AHEAD data is that when a household member dies, survivors of the deceased (usually either a surviving 
Table 3 Wealth Holdings of Surviving Households

\begin{tabular}{|c|c|c|c|c|c|c|c|c|c|c|}
\hline & 1995 & 1998 & 2000 & 2002 & 2004 & 2006 & 2008 & 2010 & 2012 & 2014 \\
\hline \multicolumn{11}{|c|}{ Means } \\
\hline Housing & 81.9 & 79.0 & 85.4 & 91.7 & 101.0 & 111.6 & 97.9 & 89.0 & 74.4 & 74.5 \\
\hline Liquid Assets & 55.5 & 50.6 & 50.1 & 55.7 & 53.9 & 54.0 & 62.6 & 57.7 & 48.2 & 50.8 \\
\hline Stocks & 38.5 & 50.5 & 54.4 & 49.5 & 56.7 & 61.2 & 57.2 & 46.6 & 52.3 & 58.1 \\
\hline Other Assets & 31.8 & 35.0 & 37.7 & 34.8 & 37.4 & 46.6 & 35.7 & 34.6 & 32.7 & 36.5 \\
\hline Debt & 1.0 & 1.0 & 0.8 & 0.4 & 0.7 & 0.7 & 0.5 & 0.6 & 0.8 & 0.2 \\
\hline Total Assets & 230.2 & 236.9 & 250.0 & 253.9 & 271.0 & 299.3 & 279.2 & 243.6 & 223.8 & 237.0 \\
\hline \multicolumn{11}{|c|}{ Medians } \\
\hline Housing & 57.0 & 54.4 & 55.0 & 50.7 & 48.5 & 45.9 & 32.6 & 42.8 & 0.0 & 0.0 \\
\hline Liquid Assets & 11.4 & 8.2 & 7.9 & 9.5 & 8.5 & 8.0 & 7.6 & 7.5 & 7.0 & 6.0 \\
\hline Stocks & 0.0 & 0.0 & 0.0 & 0.0 & 0.0 & 0.0 & 0.0 & 0.0 & 0.0 & 0.0 \\
\hline Other Assets & 2.8 & 2.7 & 2.6 & 1.3 & 1.2 & 1.1 & 0.5 & 0.0 & 0.0 & 0.0 \\
\hline Debt & 0.0 & 0.0 & 0.0 & 0.0 & 0.0 & 0.0 & 0.0 & 0.0 & 0.0 & 0.0 \\
\hline Total Assets & 103.1 & 102.4 & 105.3 & 112.5 & 109.2 & 117.1 & 112.7 & 101.6 & 89.0 & 98.1 \\
\hline Observations & 4,169 & 3,456 & 2,886 & 2,364 & 1,924 & 1,525 & 1,180 & 815 & 606 & 416 \\
\hline
\end{tabular}

Notes: Wealth holdings are measured in thousands of 2014 dollars and broken down by asset type and year. "Other assets" are the sum of the HRS asset measures for automobiles, businesses, IRAs, and "other assets."

spouse or a child) are interviewed. A key variable for our analysis is the value of the estate. This data allows us to accurately measure the wealth of single individuals at the time of their deaths. If one member of the household dies and the other survives, we measure the survivor's wealth using the usual asset variables. The HRS also asks survivors, however, if the dying spouse has left assets to nonspousal heirs. We report these "side bequests" below, along with the estates left when the final household member dies.

The HRS collects data on all out-of-pocket medical expenses, including private insurance premia and nursing home care. French et al. (2017) show that the HRS out-of-pocket medical-spending data match up well with medical-spending data from the Medical Expenditure Panel Survey and the Medicare Current Beneficiary Survey. When a household member dies, the survivors are asked about insurance payments, medical expenses immediately preceding death, and deathrelated costs, such as burial expenses. Fahle et al. (2016) show that the HRS exit interviews are essential to appropriately capture the rise of medical spending before death.

To control for socioeconomic status, we construct a measure of lifetime earnings or "permanent income" (PI). We first find each household's "non-asset" income, a pension measure that includes Social Se- 
curity benefits, defined-benefit pension income, veterans benefits, and annuities. Because there is a roughly monotonic relationship between lifetime earnings and these pension variables, post-retirement non-asset income is a good measure of lifetime PI. In earlier analyses of single households, we found that PI helps predict health, mortality, and medical spending (De Nardi et al., 2009, 2010). To create a PI measure common to both couples and singles, we follow De Nardi et al. (2019) and remove household size effects using a fixed effects regression. (See also Jones et al., 2018.) In particular, we assume that the log of nonasset income for household $i$ at age $t$ follows

$$
\ln y_{i t}=\gamma_{i}+\kappa\left(t, f_{i t}\right)+\omega_{i t},
$$

where: $\gamma_{i}$ is a household-specific effect; $\kappa\left(t, f_{i t}\right)$ is a flexible function of age and family structure $f_{i t}$ (i.e., couple, single man, or single woman); and $\omega_{i t}$ represents measurement error. The percentile ranks of the estimated fixed effects, $\widehat{\gamma}_{i}$, form our measure of PI, $\widehat{I}_{i}$. Because we study retirees, we treat $\widehat{I}_{i}$ as time-invariant.

\section{Asset Profiles}

Before beginning our main analysis, it is useful to assess overall trends. We begin by returning to Table 3, which aggregates over all surviving households. Table 3 illustrates the retirement-savings puzzle: mean and median wealth fall little, if at all, between 1995 and 2014. This finding is in part an artifact of mortality bias. ${ }^{5}$ Because the data behind Table 3 form an unbalanced panel, the tendency of wealthier households to live longer causes observed wealth to rise over time (Shorrocks, 1975; De Nardi et al., 2016). To control for mortality bias, our preferred approach in this paper is to employ a matching estimator and exploit the panel dimension of the HRS.

A more disaggregated picture emerges in Tables 4 and 5, which track the mean assets of initial couples and singles, respectively, as household members die. Table 4 shows mean assets of intact couples rise markedly over time, from $\$ 389,200$ in 1995 to $\$ 523,600$ in 2014 . Some of this increase is likely due to changes in sample composition, as only the richest couples survived intact to 2014 . Table 1 shows that by 2014, only twenty-seven couples, 2 percent of the original total, are left. The assets of singles show less of a trend. Newly single households (couples in the previous wave) have more wealth than households that had

\footnotetext{
${ }^{5}$ Correcting for mortality bias is not sufficient to eliminate the elderly savings puzzle (De Nardi et al., 2010, 2016).
} 
Table 4 Mean Assets of Initial Couples

\begin{tabular}{cccccccc}
\hline Year & $\begin{array}{c}\text { Intact } \\
\text { Couples }\end{array}$ & $\begin{array}{c}\text { Single } \\
\text { Men }\end{array}$ & $\begin{array}{c}\text { Single } \\
\text { Women }\end{array}$ & $\begin{array}{c}\text { All } \\
\text { Singles }\end{array}$ & $\begin{array}{c}\text { Newly } \\
\text { Single }\end{array}$ & $\begin{array}{c}\text { Nonspousal } \\
\text { Bequests }\end{array}$ & $\begin{array}{c}\text { Final } \\
\text { Estates }\end{array}$ \\
\hline 1995 & 389.2 & NA & NA & NA & NA & NA & NA \\
1998 & 399.2 & 303.7 & 262.1 & 275.6 & 275.6 & 32.0 & 145.8 \\
2000 & 450.0 & 293.4 & 266.8 & 274.4 & 317.4 & 75.0 & 183.7 \\
2002 & 472.5 & 279.5 & 257.8 & 263.5 & 299.4 & 57.6 & 199.7 \\
2004 & 511.2 & 332.9 & 285.8 & 297.2 & 351.6 & 47.6 & 210.8 \\
2006 & 598.8 & 409.5 & 295.7 & 322.3 & 433.9 & 98.7 & 216.6 \\
2008 & 576.1 & 378.4 & 265.0 & 290.2 & 362.9 & 62.1 & 305.1 \\
2010 & 478.7 & 408.5 & 237.7 & 273.5 & 458.0 & 75.4 & 199.2 \\
2012 & 352.1 & 346.4 & 234.4 & 255.4 & 443.3 & 26.7 & 168.3 \\
2014 & 523.6 & 364.3 & 241.4 & 263.4 & 239.1 & 12.3 & 263.3 \\
\hline
\end{tabular}

Notes: Assets are measured in thousands of 2014 dollars by household composition and year. NA denotes no observations.

been single for longer periods of time. This can be seen by comparing the column for the newly single with that for all singles.

Table 4 also shows bequests. When one spouse dies, the couple's wealth is divided between the surviving spouse and other heirs, such as children. Comparing the wealth of the newly single with nonspousal bequests shows that most of the wealth is left to the surviving spouse; in several years, assets left to nonspousal heirs are less than one-quarter the size of spousal bequests. The last column of the table shows the bequests left when the final household member dies. (This includes cases where both spouses die in the same interval.) Final estates are almost always smaller than the assets of the living.

Table 5 shows asset trajectories for households that were already single in 1995. The profiles for this group have much less of an upward slope than their counterparts in Table 4, suggesting that single households are more likely to decumulate their wealth; De Nardi et al. (2019) report similar findings. Mean estates tend to be smaller than the mean asset holdings of survivors, but this is not always the case.

\section{METHODOLOGY}

To measure how assets evolve around the time of death, we compare the assets of households that experienced a death to those of households that did not. Our principal econometric concern is that these groups might differ systematically for reasons besides death. For example, poorer households tend to die at younger ages. Therefore, at any age, households with deaths will have fewer assets, not because they ran 
Table 5 Mean Assets of Initial Singles

\begin{tabular}{lcccc}
\hline & \multicolumn{2}{c}{ Single Men in 1995 } & \multicolumn{2}{c}{ Single Women in 1995 } \\
Year & Survivors & Final Estates & Survivors & Final Estates \\
\hline 1995 & 206.5 & NA & 154.9 & NA \\
1998 & 204.5 & 121.5 & 161.1 & 82.1 \\
2000 & 210.7 & 88.2 & 165.9 & 68.0 \\
2002 & 233.6 & 129.7 & 169.4 & 107.5 \\
2004 & 208.7 & 188.8 & 181.9 & 140.9 \\
2006 & 242.9 & 241.0 & 194.0 & 175.1 \\
2008 & 22.3 & 128.5 & 185.8 & 152.6 \\
2010 & 221.2 & 272.7 & 149.6 & 114.8 \\
2012 & 272.5 & 108.3 & 148.9 & 122.4 \\
2014 & 235.4 & 227.8 & 137.6 & 169.7 \\
\hline
\end{tabular}

Notes: Assets are measured in thousands of 2014 dollars by household composition and year. NA denotes no observations.

down their wealth as death approached, but simply because they were more likely to have been poor all along.

In a nutshell, our approach for dealing with this problem is to construct a control group that is, except for not experiencing deaths, similar to the treatment group suffering the deaths. To describe our approach formally, let $A_{i, t}$ denote measured assets for household $i$ at time $t$. We allow $A_{i, t}$ to be mismeasured but assume that any such mismeasurement takes the form of zero-mean classical measurement error. Next, let $T_{i}$ denote the calendar year of the HRS wave when household $i$ reports a death. By way of example, if the husband in couple $i$ dies in 1999, $T_{i}$ will equal 2000, the year of the next HRS wave. Finally, let $d_{i}(t)=t-T_{i}$ measure the distance between the current period and death, and let $A_{i, d}$ denote the assets held by household $i$ when its death is $d$ periods away.

We proceed in two steps. First, among couples that lose a spouse, ${ }^{6}$ we estimate the fixed effects regression

$$
\begin{aligned}
A_{i, t}= & A_{i, d_{i}(t)} \\
= & f_{i}+a_{1} \times 1\left\{d_{i}(t)=-4\right\} \\
& +a_{2} \times 1\left\{d_{i}(t)=-2\right\}+a_{3} \times 1\left\{d_{i}(t)=0\right\} \\
& +a_{4} \times 1\left\{d_{i}(t)=2\right\}+a_{5} \times 1\left\{d_{i}(t)=4\right\}+e_{i, t},
\end{aligned}
$$

\footnotetext{
${ }^{6}$ We restrict the treatment group to couples whose deaths occur no earlier than 2000 , giving us at least two waves of predeath data. We also remove observations more than three periods before death $(d<-6)$ or more than two periods after death $(d>4)$.
} 
using the 0-1 indicator function $1\{\cdot\}$ to denote distance-from-death dummy variables. We estimate a similar regression for singles, but by necessity stop at the date of death. Because the fixed effect $f_{i}$ is potentially correlated with the date of death, the key coefficients in equation (2) are $a_{1}$ through $a_{5}$, which show the extent to which assets rise or fall relative to their value six years before death (the omitted indicator category). The transitory residual $e_{i, t}$ is zero mean and by assumption uncorrelated with $d_{i}(t)$.

Second, we construct and analyze a control group. For each household $i$ in the treatment groups above, we find in the data a household $m(i)$ that did not experience a death at $T_{i}$ but is otherwise similar to $i$. In particular, for each household $i$, we find the set of households that: experience a death six to ten years after $T_{i} ;{ }^{7}$ are observed at date $T_{i}$; have the same initial (1995) household composition; differ from $i$ in age by no more than ten years; differ from $i$ in PI percentile by no more than 15 percentage points; differ from $i$ in terms of 1995 assets by less than $\$ 5,000$ or 2.5 percent. ${ }^{8}$ We then use a random number generator to pick one household out of this set, giving all members in the set the same probability of being selected.

Household $m(i)$ is given the same "death date" $\left(T_{i}\right)$ as household $i$ and thus the same values of $d$. We then estimate

$$
\begin{aligned}
A_{m(i), t}= & f_{m(i)}+b_{1} \times 1\left\{d_{i}(t)=-4\right\} \\
& +b_{2} \times 1\left\{d_{i}(t)=-2\right\} \\
& +b_{3} \times 1\left\{d_{i}(t)=0\right\} \\
& +b_{4} \times 1\left\{d_{i}(t)=2\right\} \\
& +b_{5} \times 1\left\{d_{i}(t)=4\right\}+e_{m(i), t} .
\end{aligned}
$$

The differences between the treatment group coefficients in equation (2) and the control group coefficients in equation (3) are our measure of the asset decline associated with death.

\section{RESULTS}

\section{Total Wealth}

Figure 1 shows the asset trajectory of couples that lost a spouse (labeled "Death in Household") along with the asset trajectory for couples in the control group ("No Death"). Panel (a) shows that six years prior to

\footnotetext{
${ }^{7}$ Fadlon and Nielsen (2019) impose a similar restriction in their analysis of health shocks.

${ }^{8}$ If we are unable to find a potential match, we relax the asset criteria to either $\$ 10,000$ or 5 percent.
} 
the spouse's death - the point labeled "-6" on the horizontal axis - both groups have average asset holdings of around $\$ 320,000$. Initially, the control group holds almost $\$ 20,000$ less, but by the time of death, the gap between the groups has widened to around $\$ 70,000$. This suggests that assets fall by about $\$ 90,000$ in the six years preceding the death of the spouse because of his or her death. Panel (b) shows the deathrelated asset decline itself along with 95 percent confidence intervals. ${ }^{9}$ Much of the decline occurs in the final two years before death. The gap between the treatment and control groups continues to widen in the years following the death. This may reflect additional death-related effects, the loss of one spouses's income - when a spouse dies, annuitized income falls by around one-third (De Nardi et al., 2019) — or still other differences between intact couples and singles.

In Figure 2, we sort couples by initial wealth - above and below the median - and repeat the comparisons. Comparing the left- and righthand panels of this figure reveals that the wealthier couples experience a much larger asset drop when a spouse dies. For households with high initial wealth, the drop is $\$ 160,000$.

Figure 3 shows the assets of singles who die, along with the assets of comparable survivors. Comparing the two profiles indicates that assets fall by $\$ 20,000$ around the time of death. Figure 4 provides separate comparisons for the high- and low-wealth groups. Once again, the assets of high-wealth households decline by much larger amounts around the time of death, by close to $\$ 40,000$. Low-wealth singles show no death-related decline at all.

\section{Home Equity}

Table 3 shows that a significant fraction of household wealth takes the form of home equity. Housing is typically less liquid than other assets: there are transaction costs associated with selling a house (Yang, 2009), and research suggests that older individuals place a high weight on remaining in their homes (Nakajima and Telyukova, 2019, 2017; McGee, 2019). Nonetheless, individuals nearing the ends of their lives may need to enter long-term care facilities, freeing their homes for sale. ${ }^{10}$

\footnotetext{
${ }^{9}$ The confidence intervals are based on the standard errors of the estimated coefficients, which are assumed to be independent. Because of the underlying matching procedure, this assumption is not strictly correct (Abadie and Imben, 2006). Fadlon and Nielsen (2019) employ a similar approach.

${ }^{10}$ A related question is whether nursing home residents who receive Medicaid benefits must sell their homes. If only one spouse is institutionalized, the other spouse can, within limits, keep the marital home. The treatment of housing for institutionalized singles is more involved (De Nardi et al., 2012).
} 
Figure 1 Mean Wealth around Death, Initial Couples

(a) Levels

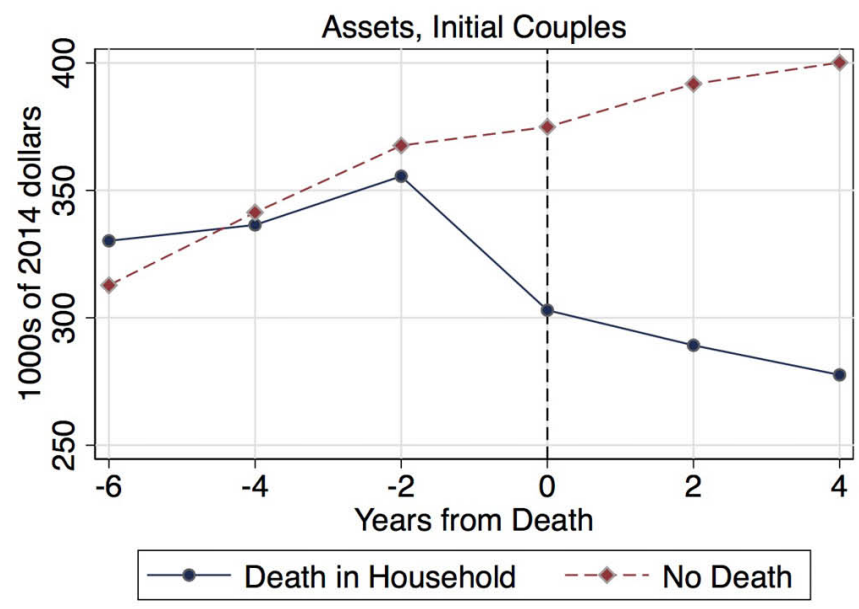

(b) Differences in Differences (with 95\% confidence intervals)

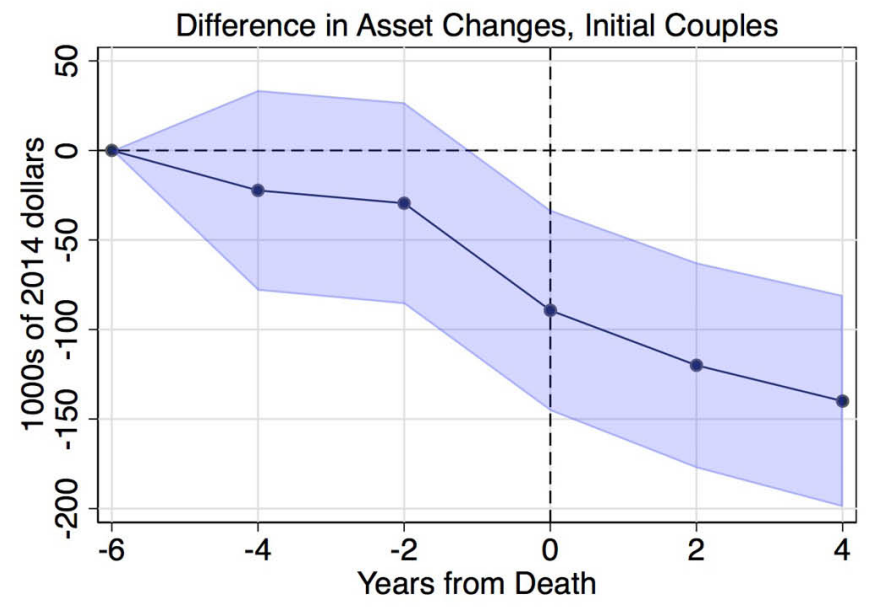

In Figures 5 and 6, we divide total assets between home equity and the remainder, which we label "financial wealth," and compare the treatment and control groups along these two dimensions. Figure 5 shows that among couples, home equity falls by less than $\$ 15,000$, while financial wealth falls by about $\$ 70,000$. In contrast to couples, who mostly deplete financial wealth, Figure 6 shows that singles treat home 


\section{Figure 2 Mean Wealth around Death by Initial Asset Level, Initial Couples}

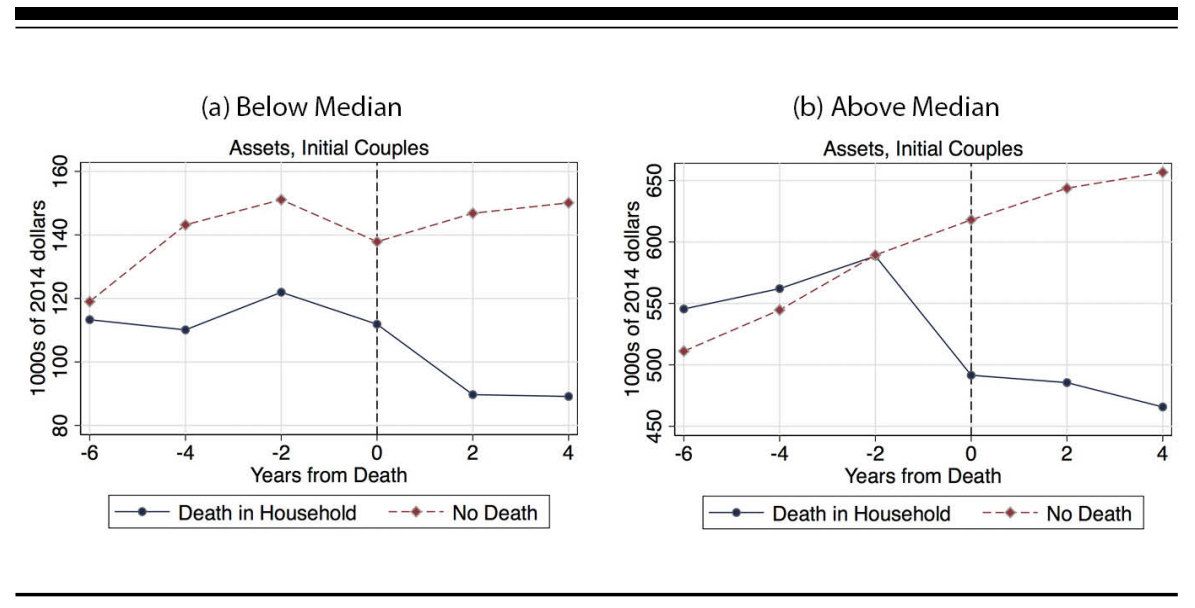

equity and financial wealth in similar ways. Because we are unable to decompose the estate data, for singles the comparison ends one wave before death. (The treatment group is given a placeholder value at $d=0$.) Both asset groups show a decline of about $\$ 10,000 .^{11}$

\section{Medical Expenses}

Figures $1-6$ show that assets decline significantly around the time of death, especially for wealthier households. How much of this decline is attributable to medical expenses? Panel (a) of Figure 7 shows that by the time of death, out-of-pocket medical expenditures for single households have risen by $\$ 9,300$ per year. Our medical-spending measure includes death expenses such as funeral expenses. Interpreting this number is not immediate. In each wave, the HRS asks respondents how much they spent in the previous two years. Dividing this number by two produces an annual value. The $\$ 9,300$ increase in annual medical spending thus represents an additional $\$ 18,600$ of expenses during the two years prior to death. ${ }^{12}$ Of this amount, funeral and other death expenses account for more than $\$ 7,200$. Including the additional spending incurred in the preceding two years (the axis interval -4 to -2 ) generates another $\$ 7,500$, along with another $\$ 3,900$ in the two years

\footnotetext{
${ }^{11}$ The measured declines in home equity and financial wealth do not sum to the measured decline in total wealth because of missing data.

${ }^{12}$ Although most individuals die less than two years after their last interview, for simplicity we divide their terminal spending by two.
} 
Figure 3 Mean Wealth around Death, Initial Singles

(a) Levels

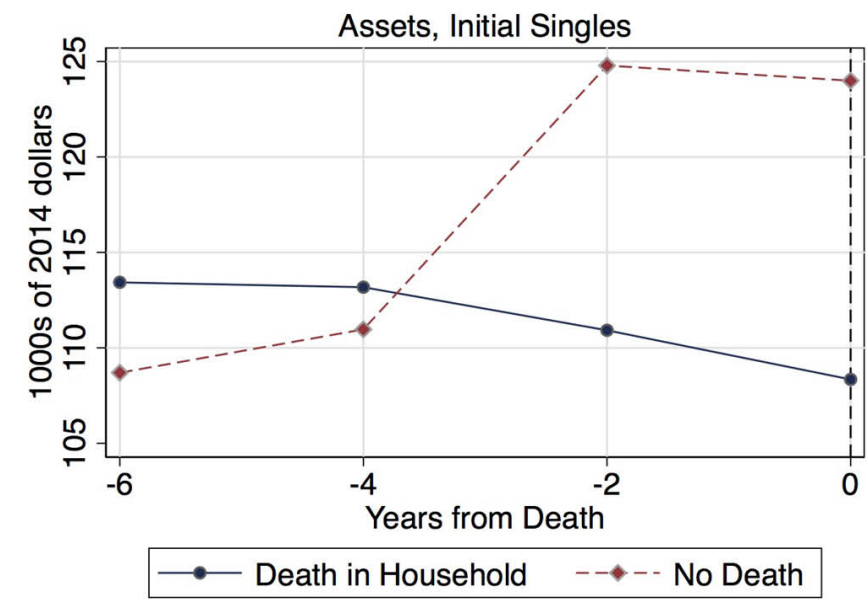

(b) Differences in Differences (with 95\% confidence intervals)

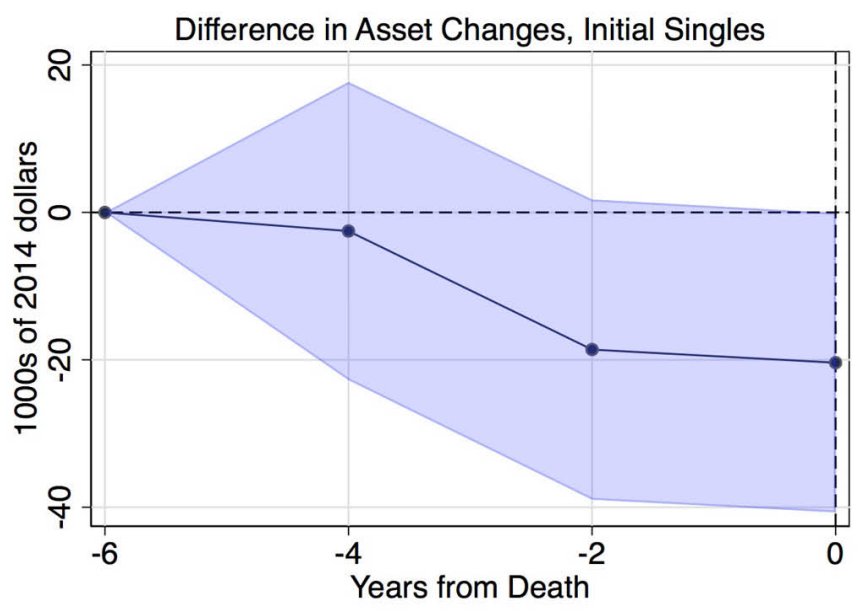

preceding that. In short, medical expenses are more than sufficient to explain the $\$ 20,000$ decline in assets observed in single households.

This is not the case for couples. As a spouse approaches death, average household medical spending for couples increases by about $\$ 8,200$ per year. This is a little smaller than the increase in expenses experienced by singles. The gap may reflect the ability of one spouse to care 
Figure 4 Mean Wealth around Death by Initial Asset Level, Initial Singles
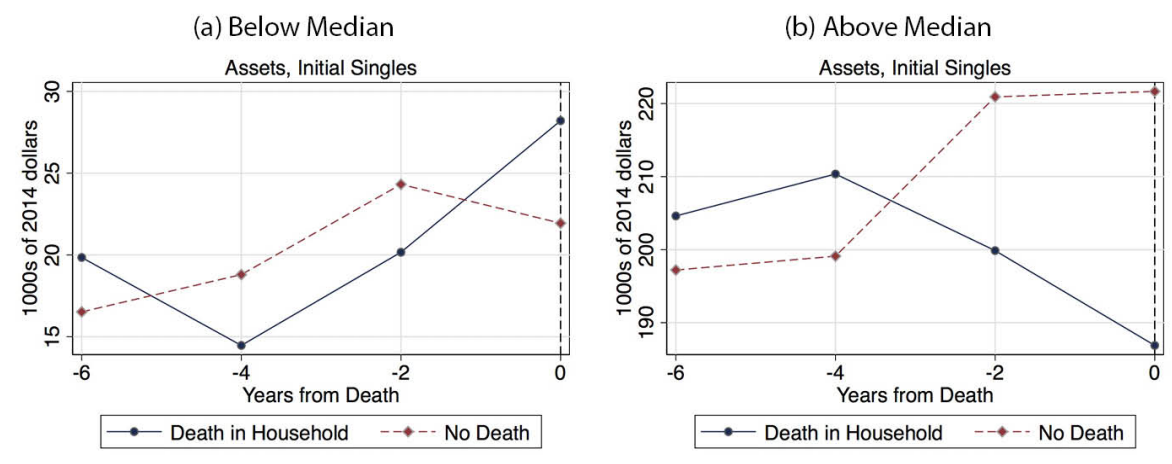

Figure 5 Mean Wealth around Death by Asset Type, Initial Couples
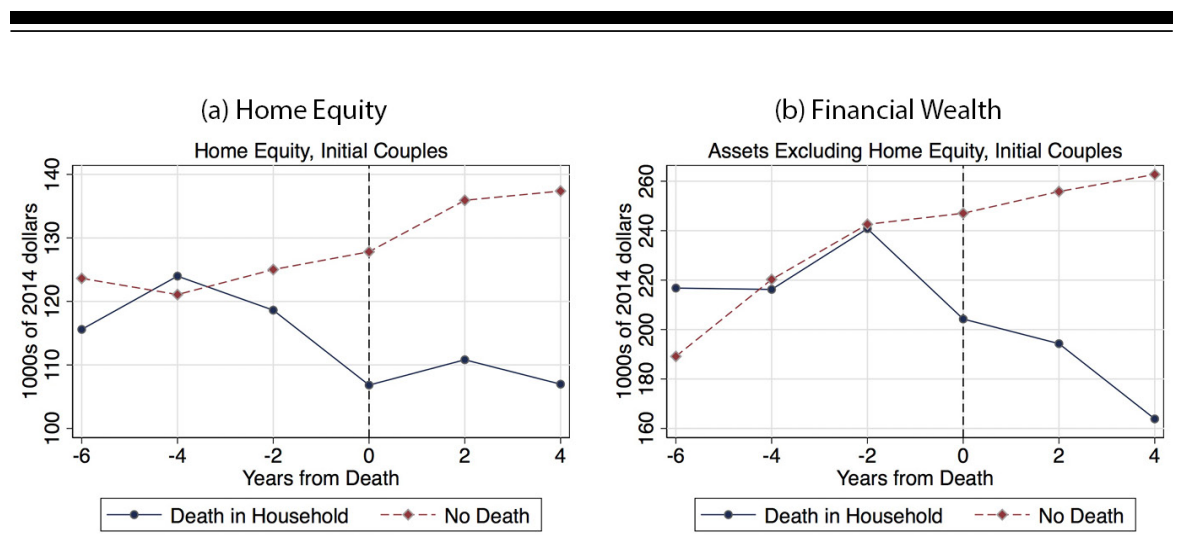

for the other or differences in the age and sex of the deceased; because women live longer than men, the husband is usually the first spouse to die, while most older singles are women. Overall, in the six years preceding death, couples incur just over $\$ 22,000$ of additional spending, around one quarter of the asset decline of $\$ 90,000$ shown in Figure 1. Where might the remainder come from?

One possibility is that transfers to nonspousal heirs increase around the time of the first spouses' deaths, either inter-vivos or through bequests. The nonspousal bequests shown in Table 4 are in fact more 


\section{Figure 6 Mean Wealth around Death by Asset Type, Initial Singles}

(a) Home Equity

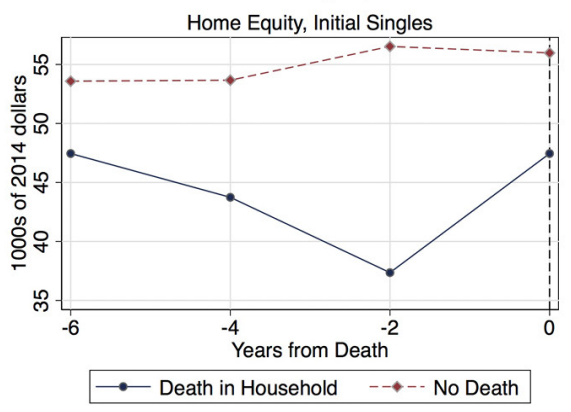

(b) Financial Wealth

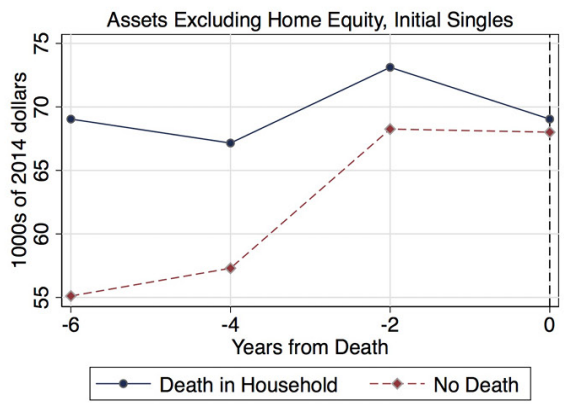

than sufficient to explain the difference: the households included in our event study on average bequeathed more than $\$ 105,000$ to their nonspousal heirs.

Another possibility is an increase in nonmedical consumption. For example, some health-related expenditures, such as stair lifts, might not be recorded as medical spending. Alternatively, couples may expect a fall in consumption after a spousal death that is larger than the fall in future annuity income. This would encourage couples to consume more when a spouse's death is imminent. In the absence of detailed consumption data, such possibilities are difficult to assess.

\section{Comparison with French et al. (2006)}

The exercises most similar to ours appear in Figures 1 and 2 of French et al. (2006). Figure 1 of their paper showed that the assets of dying singles fell, relative to their surviving peers, by about $\$ 64,000$ in 1998 prices; applying the CPI-U, this translates to $\$ 93,000$ in 2014 prices. Figure 2 of their paper showed that as individuals approached death, their out-of-pocket medical spending rose by $\$ 5,500$ in 1998 prices (\$8,000 in 2014 prices). While the increase in out-of-pocket spending estimated in French et al. (2006) is similar to ours, the fall in assets they estimate is nearly four times as large.

We see three potential explanations for this discrepancy: data revisions; the introduction of our truncation procedure; and the addition of newer waves of data. First of all, the HRS has updated the way in which it collects and processes its asset measures, especially bequests. 


\section{Figure 7 Out-of-Pocket Medical Spending and Death Expenses around Death by Household Type}
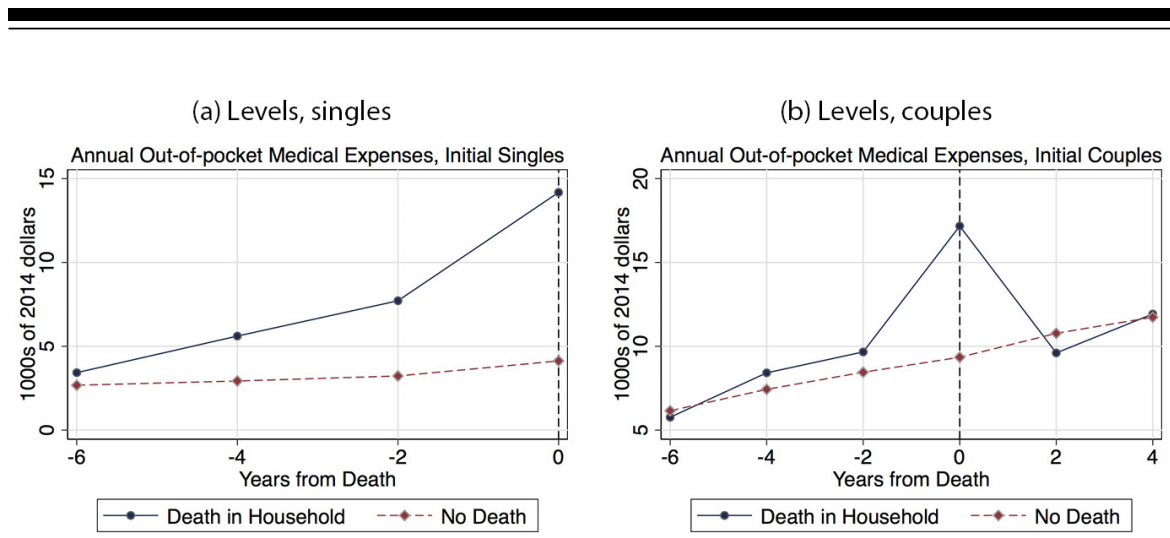

(c) Differences in Differences, singles

(b) Differences in Differences, couples
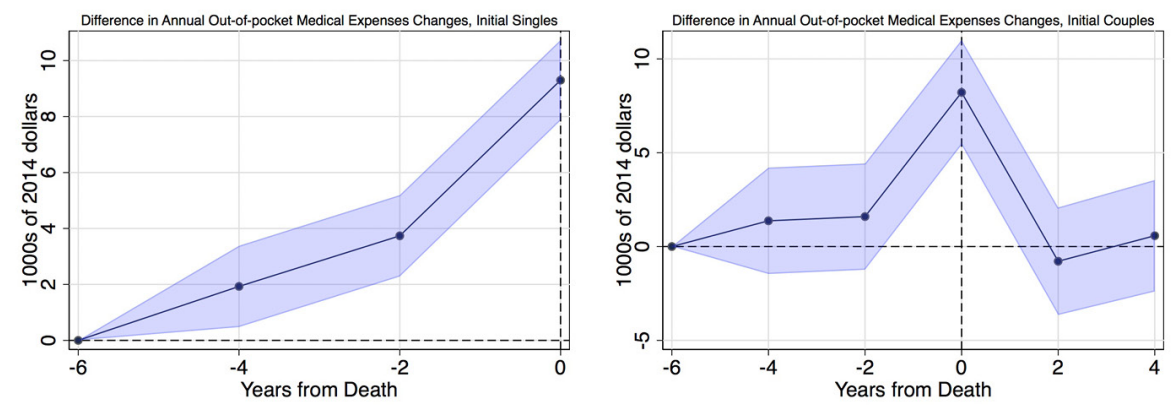

These changes take many forms. For example, the families of many deceased individuals participate in "post-exit" interviews. Post-exit interview data are used in the current paper, but were not used in French et al. (2006). In addition, we made several improvements to our procedures for imputing the assets of those who have died.

To measure the effects of the data revisions, in Table 6 we update part of French et al.'s (2006) Tables 4 and 5 with our data and compare it to the original results. The first two columns of Table 6 compare the assets of singles who died by 2002 to the assets of those who survived. ${ }^{13}$ (We discuss the results for couples below.) The top panel contains the original results from French et al. (2006) updated to 2014 prices. The first two columns of this panel reveal that the assets of surviving singles

\footnotetext{
${ }^{13}$ These are raw data comparisons using all observations. There is no matching.
} 
Table 6 Mean Assets by Household Demographic Status in 1995 and 2002 for Different HRS Vintages

\begin{tabular}{lccccc}
\hline & & & & \\
& Single in & $\mathbf{1 9 9 5}$ & \multicolumn{2}{c}{ Married in 1995 } \\
2002 Household Structure & Single & Dead & Married & Single & Dead \\
\hline Data in French et al. (2006) & & & & & \\
1995 Assets & 240.1 & 214.4 & 502.4 & 332.4 & 389.5 \\
2002 Assets & 241.4 & 147.3 & 496.3 & 296.4 & 326.5 \\
Differences in Differences & NA & -68.4 & NA & -29.9 & NA \\
Observations & 1,353 & 1,362 & 457 & 504 & 204 \\
Updated Data, no truncation & & & & & \\
1995 Assets & 220.7 & 197.5 & 531.1 & 384.1 & 437.0 \\
2002 Assets & 220.8 & 143.7 & 516.9 & 304.2 & 911.0 \\
Differences in Differences & NA & -53.9 & NA & -65.7 & NA \\
Observations & 1,438 & 1,407 & 473 & 494 & 191 \\
Updated Data, with truncation & & & & & \\
1995 Assets & 194.9 & 130.9 & 481.8 & 322.5 & 330.4 \\
2002 Assets & 178.8 & 91.3 & 472.5 & 263.5 & 189.0 \\
Differences in Differences & NA & -23.5 & NA & -49.7 & NA \\
Observations & 1,417 & 1,381 & 466 & 481 & 187 \\
\hline
\end{tabular}

Notes: Assets are measured in thousands of 2014 dollars. "Differences in differences" are calculated as the change in assets between 1995 and 2002 for households with a death minus the change in assets for households who remain intact.

increased by $\$ 1,300$ over the seven-year interval, while the assets of those who died fell by about $\$ 67,000$, for a total death-related drop of over $\$ 68,000$. The second panel shows results derived from the updated data prior to our truncation procedure. The updated results for singles are fairly similar to those for French et al. (2006); the death-related decline in assets is smaller but still in excess of $\$ 50,000$.

The third panel of Table 6 shows the results that emerge after we drop observations with assets above the ninety-ninth percentile. Background estimates show that even though our truncation procedure reduces mean assets in general, it has only a modest effect on our estimated asset dynamics, reducing the fall in assets associated with the death of a single by $\$ 5,000$. However, within the subset of the data corresponding to French et al.'s (2006) Tables 4 and 5, truncating the top 1 percent of the asset distribution significantly reduces the estimated death-related decline from $\$ 53,900$ to $\$ 23,500$.

Yet another difference is that we now have more years of data. To assess the importance of this change, the left side of Table 7 shows the assets of singles in the two waves preceding deaths, along with their 
Table 7 Mean Assets Prior to Death by Wave of Death

\begin{tabular}{|c|c|c|c|c|c|c|c|c|}
\hline \multirow[b]{3}{*}{$\begin{array}{l}\text { Year of } \\
\text { Death }\end{array}$} & \multicolumn{4}{|c|}{ Singles Who Die } & \multicolumn{4}{|c|}{ Couples Who Become Singles } \\
\hline & \multirow[b]{2}{*}{ Count } & \multicolumn{2}{|c|}{ Prior to Death } & \multirow[b]{2}{*}{$\begin{array}{c}\text { Final } \\
\text { Estates }\end{array}$} & \multirow[b]{2}{*}{ Count } & \multicolumn{2}{|c|}{ Prior to Death } & \multirow[b]{2}{*}{$\begin{array}{c}\text { Final } \\
\text { Estates }\end{array}$} \\
\hline & & $\begin{array}{c}\text { Two } \\
\text { Waves }\end{array}$ & $\begin{array}{c}\text { One } \\
\text { Wave }\end{array}$ & & & $\begin{array}{c}\text { Two } \\
\text { Waves }\end{array}$ & $\begin{array}{l}\text { One } \\
\text { Wave }\end{array}$ & \\
\hline 2000 & 463 & 139.6 & 111.2 & 72.4 & 210 & 329.4 & 327.3 & 312.5 \\
\hline 2002 & 409 & 117.0 & 117.8 & 110.9 & 164 & 362.2 & 375.7 & 300.8 \\
\hline 2004 & 355 & 156.5 & 163.8 & 149.8 & 128 & 376.3 & 392.1 & 360.6 \\
\hline 2006 & 276 & 160.0 & 163.9 & 183.6 & 97 & 446.1 & 461.2 & 406.6 \\
\hline 2008 & 238 & 164.4 & 165.9 & 149.9 & 58 & 421.3 & 436.1 & 387.2 \\
\hline 2010 & 222 & 206.6 & 160.0 & 133.0 & 60 & 722.0 & 593.0 & 442.3 \\
\hline 2012 & 103 & 200.1 & 154.3 & 120.9 & 25 & 788.5 & 654.1 & 421.6 \\
\hline 2014 & 87 & 151.0 & 154.0 & 173.8 & 18 & 334.9 & 183.5 & 225.8 \\
\hline All & 2,153 & 153.7 & 142.8 & 128.0 & 760 & 412.5 & 402.4 & 347.6 \\
\hline
\end{tabular}

Note: Assets are measured in thousands of 2014 dollars.

estates. ${ }^{14}$ Each row of the table indexes a particular wave, allowing us to compare the asset trajectories of people who die in early waves to those of people who die later. The first two rows of Table 7 , for those who die in 2000 and 2002, use data from waves available to French et al. (2006). The average asset drop for this group is almost $\$ 40,000$. This is larger than the overall sample average of $\$ 26,000$, suggesting that using later waves might help explain why our results differ from French et al.'s (2006). Once again, data improvements almost surely play a role. The newer waves of "exit data" ask whether the reported value of the estate includes the value of the decedent's home. If the respondent states that the value of the estate does not include the value of the home, we add the home's value to the total. (This happens about 7 percent of the time.) This question was not asked in the earlier waves available to French et al. (2006), leading to a downward bias in the estate measure and an upward bias in the estimated fall in assets.

The right-hand sides of Tables 6 and 7 show results for couples who become singles. Table 6 shows that the data revisions raise the estimated death-related effects, even after truncating the largest observations. Expanding the sample period reinforces this change: Table 7 shows that, in contrast to the death of a single, the asset declines associated with the death of a spouse are larger in later waves.

\footnotetext{
${ }^{14}$ As with Table 6, Table 7 uses all households, making no attempt to construct a matched sample. The results in these tables are thus not directly comparable to those in Figures 1 and 3.
} 


\section{CONCLUSIONS AND FUTURE WORK}

We find that a household's wealth declines significantly when one of its members dies. Our estimates suggest that in the six years preceding their deaths, the assets of dying singles decline by $\$ 20,000$ more than those of otherwise similar survivors. The assets of couples who lose a spouse fall by $\$ 90,000$, a much larger amount. These falls in wealth are concentrated among wealthier households. Households in the bottom half of the (initial) wealth distribution experience virtually no deathrelated declines whatsoever.

Having established that assets often fall at the time of death, the next order of business is understanding why. From an accounting perspective, elevated medical spending can account for all of the average asset decline observed for singles and around one-quarter of the decline observed for couples. This leaves much of the asset decline for couples unexplained, but bequests from the dying spouse to nonspousal heirs, such as children, are enough to cover it. These "side" bequests are in fact larger than the unexplained decline. Thus, more empirical work on these bequests, along with similarly-timed inter-vivos transfers, is in order. It is also important to examine the potential economic motivations behind side bequests.

What do our results tell us about the elderly savings puzzle? Our findings are suggestive, but only modestly so. For couples, the average fall in assets at the time of death is much larger than the contemporaneous increase in medical spending. Small average spending levels do not preclude strong precautionary motives. Our findings nonetheless suggest that couples save for reasons beyond medical spending. In the case of singles, elevated medical spending is sufficient to explain the decline in assets, and the increase in spending is larger than that observed for couples. We find little evidence that their consumption rises near the time of death. This may suggest that older singles place a large weight on leaving bequests. Alternatively, it may suggest that older singles are extremely risk-averse and remain uncertain about their time of death and end-of-life medical needs until the very end.

Our results may well have more discriminatory power if they are used to inform structural analyses. By way of example, in De Nardi et al. (2019), we develop a dynamic model of saving for older households that accounts explicitly for the transition from couples to singles. Matching the asset trajectories associated with these transitions provides a potentially important source of identification. 


\section{REFERENCES}

Abadie, Alberto, and Guido W. Imbens. 2006. "Large Sample Properties of Matching Estimators for Average Treatment Effects." Econometrica 74 (January): 235-67.

Ameriks, John, Joseph Briggs, Andrew Caplin, Matthew D. Shapiro, and Christopher Tonetti. 2018. "The Long-Term-Care Insurance Puzzle: Modeling and Measurement." Manuscript.

Bernheim, B. Douglas, Andrei Shleifer, and Lawrence H. Summers. 1985. "The Strategic Bequest Motive." Journal of Political Economy 93 (December): 1045-76.

Board of Governors of the Federal Reserve System. 2019. "Survey of Consumer Finances, Historic Tables and Charts," September.

Braun, R. Anton, Karen A. Kopecky, and Tatyana Koreshkova. 2019. "Old, Frail, and Uninsured: Accounting for Puzzles in the U.S. Long-Term Care Insurance Market." Econometrica 87 (May): 981-1019.

Cocco, João F., and Paula Lopes. 2019. "Aging in Place, Housing Maintenance, and Reverse Mortgages," Review of Economic Studies 87 (September): 1799-1836.

De Nardi, Mariacristina, Eric French, and John Bailey Jones. 2009. "Life Expectancy and Old Age Savings." American Economic Review 99 (May): 110-15.

De Nardi, Mariacristina, Eric French, and John Bailey Jones. 2010. "Why Do the Elderly Save? The Role of Medical Expenses," Journal of Political Economy 118 (February): 39-75.

De Nardi, Mariacristina, Eric French, and John Bailey Jones. 2016. "Savings After Retirement: A Survey." Annual Review of Economics 8 (October): 177-204.

De Nardi, Mariacristina, Eric French, John Bailey Jones, and Angshuman Gooptu. 2012. "Medicaid and the Elderly." Federal Reserve Bank of Chicago Economic Perspectives 36 (February): $17-34$.

De Nardi, Mariacristina, Eric French, John Bailey Jones, and Rory McGee. 2019. "Couples' and Singles' Savings after Retirement." Work in progress.

Dynan, Karen E., Jonathan Skinner, and Stephen P. Zeldes. 2002. "The Importance of Bequests and Life-Cycle Saving in Capital 
Accumulation: A New Answer." American Economic Review 92 (May): 274-78.

Fadlon, Itzik, and Torben Heien Nielsen. 2019. "Family Health Behaviors." American Economic Review 109 (September): 3162-91.

Fahle, Sean, Kathleen McGarry, and Jonathan Skinner. 2016. "Out-of-Pocket Medical Expenditures in the United States: Evidence from the Health and Retirement Study." Fiscal Studies 37 (November): 785-819.

French, Eric, John Bailey Jones, and Jeremy McCauley. 2017. "The Accuracy of Economic Measurement in the Health and Retirement Study." Forum for Health Economics and Policy 20 (October): 1-16.

French, Eric, John Bailey Jones, Elaine Kelly, and Jeremy McCauley. 2018. "End-of-Life Medical Expenses." Federal Reserve Bank of Richmond Working Paper No. 18-18, December.

French, Eric, Mariacristina De Nardi, John Bailey Jones, Olyesa Baker, and Phil Doctor. 2006. "Right before the End: Asset Decumulation at the End of Life." Economic Perspectives 30 (January): 2-13.

Jones, John Bailey, Mariacristina De Nardi, Eric French, Rory McGee, and Justin Kirschner. 2018. "The Lifetime Medical Spending of Retirees." Federal Reserve Bank of Richmond Economic Quarterly 104 (Third Quarter): 103-35.

Kopczuk, Wojciech. 2007. "Bequest and Tax Planning: Evidence from Estate Tax Returns." Quarterly Journal of Economics 122 (November): 1801-54.

Kvaerner, Jens. 2019. "Intergenerational Altruism: Estimates Based on News about Expected Mortality." September. Available at SSRN 2985465.

McGee, Rory. 2019. "Old Age Savings and House Price Shocks." Manuscript.

Nakajima, Makoto, and Irina A. Telyukova. 2017. "Reverse Mortgage Loans: A Quantitative Analysis" Journal of Finance 72 (December): 911-50.

Nakajima, Makoto, and Irina A. Telyukova. 2019. "Home Equity in Retirement." International Economic Review 61 (January): 573-616. 
Poterba, James M., Steven F. Venti, and David A. Wise. 2011. "The Composition and Drawdown of Wealth in Retirement." Journal of Economic Perspectives 25 (Fall): 95-118.

Poterba, James M., Steven F. Venti, and David A. Wise. 2017. "The Asset Cost of Poor Health." Journal of the Economics of Ageing 9 (June): 172-84.

Poterba, James M., Steven F. Venti, and David A. Wise. 2018. "Longitudinal Determinants of End-of-Life Wealth Inequality." Journal of Public Economics 162 (June): 78-88.

Rohwedder, Susann, Steven J. Haider, and Michael D. Hurd. 2006. "Increases in Wealth among the Elderly in the Early 1990s: How Much Is Due to Survey Design?" Review of Income and Wealth 52 (November): 509-24.

Shorrocks, Anthony F. 1975. "The Age-Wealth Relationship: A Cross-Section and Cohort Analysis." Review of Economics and Statistics 57 (May): 155-63.

Suari-Andreu, Eduard, Raun van Ooijen, Rob J. M. Alessie, and Viola Agelini. 2019. "Giving with a Warm Hand: Evidence on Estate Planning and Bequests." Netspar Design Paper 120, April.

Yang, Fang. 2009. "Consumption over the Life Cycle: How Different Is Housing?" Review of Economic Dynamics 12 (July): 423-43. 